Heins, M.J., Knoop, H., Lobbestael, J., Bleijenberg, G. Childhood maltreatment and the response to cognitive behavior therapy for chronic fatigue syndrome. Journal of

\begin{tabular}{l|l} 
Postprint & 1.0
\end{tabular}

Version

Journal website http://www.jpsychores.com/article/S0022-3999(11)00152-8/abstract

Pubmed link http://www.ncbi.nlm.nih.gov/pubmed/22118383

DOI 10.1016/j.jpsychores.2011.05.005

This is a NIVEL certified Post Print, more info at http://www.nivel.eu

\title{
Childhood maltreatment and the response to cognitive behavior therapy for chronic fatigue syndrome
}

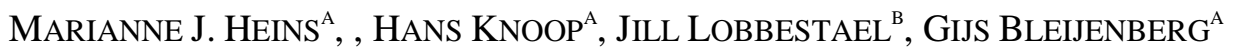 \\ ${ }^{a}$ Expert Centre for Chronic Fatigue, Radboud University Nijmegen Medical Centre, The \\ Netherlands \\ ${ }^{\mathrm{b}}$ Departments of Clinical Psychological Science, Maastricht University, The Netherlands
}

\begin{abstract}
Objective: To examine the relationship between a history of childhood maltreatment and the treatment response to cognitive behavior therapy for chronic fatigue syndrome (CFS).

Methods: A cohort study in a tertiary care clinic with a referred sample of 216 adult patients meeting the Centers for Disease Control and Prevention criteria for CFS, and starting cognitive behavior therapy. Main outcome measures changes between pre- and post therapy in fatigue (Checklist Individual Strength fatigue subscale), disabilities (Sickness Impact Profile total score), physical functioning (short form 36 health survey subscale) and psychological distress (Symptom checklist 90 total score).

Results: At baseline, patients with a history of childhood maltreatment had significantly more limitations and a higher level of psychological distress, but were not more severely fatigued. Change scores on the outcome measures after cognitive behavior therapy did not differ significantly between patients with or without a history of childhood maltreatment, or between the different types of childhood maltreatment. However, patients with a history of childhood maltreatment still experienced more limitations and a higher level of psychological distress after CBT.

Conclusions: A history of childhood maltreatment was not related to the treatment response of cognitive behavior therapy for CFS. In patients with a history of childhood maltreatment CFS symptoms can be treated with CBT just as well as those without.
\end{abstract}

\section{AbBreViations \\ CDC, Centers for Disease Control and Prevention; \\ CFS, chronic fatigue syndrome;}


Heins, M.J., Knoop, H., Lobbestael, J., Bleijenberg, G. Childhood maltreatment and the response to cognitive behavior therapy for chronic fatigue syndrome. Journal of

CI, confidence interval;

CIS, Checklist Individual Strength;

CM, childhood maltreatment;

CTQ SF, childhood trauma questionnaire short form;

OR, Odds Ratio;

RCT, randomized clinical trial;

SCL, Symptom checklist 90;

SF36, short form 36 health survey;

SIP, sickness impact profile

\section{INTRODUCTION}

Chronic fatigue syndrome (CFS) is an often long-lasting condition [1], that has profound impact on the daily life of patients [2]. The diagnostic criteria for CFS, as defined by the Centers for Disease Control and Prevention (CDC), include the experience of severe and medically unexplained fatigue for more than six months that causes cause severe impairment in daily functioning [3] and [4].

Previous studies have found an increased prevalence of childhood maltreatment in both patients with CFS and chronic fatigue (i.e. any fatigue lasting longer than

6 months but not meeting full CDC criteria). Most of them were nested case-control

studies in the general population [5], [6], [7], [8] and [9], except for one small casecontrol study conducted in a specialist clinic [10]. Two studies did not find an increased prevalence of childhood maltreatment in CFS patients [11] and [12], although one of them did find an increased prevalence in patients with chronic fatigue not meeting CDC criteria. In addition, two studies found that the risk of being a CFS patient increased with a higher exposure to childhood maltreatment [5] and [6]. So childhood maltreatment seems to make a person more vulnerable to become chronically fatigued.

Cognitive behavior therapy (CBT) is an evidence based intervention for CFS that leads to a significant reduction in fatigue and impairment, as has been shown by two meta-analyses [13] and [14]. A subgroup of CFS patients shows a complete recovery following CBT [15]. CBT is based on a model that encompasses different fatigue related cognitions and behaviors, thought to perpetuate symptoms in CFS patients[16] and [17]. These include attributing complaints to a somatic cause, low levels of physical activity, low sense of control over symptoms and focusing on bodily symptoms. During CBT the therapist helps the patient to change these perpetuating factors to become less fatigued and disabled.

Childhood maltreatment seems to predispose patients to develop CFS. According to the model underlying CBT for CFS, predisposing factors only play a role in the development of CFS, not in the continuation of symptoms. It would therefore, at first sight, not seem likely that exposure to childhood maltreatment would have an effect on the response to CBT. However, there are several possible pathways as to how a history of childhood maltreatment could have a negative effect on CBT for CFS. First, childhood maltreatment has been related to psychological distress (e.g. depression, anxiety) in later life [7], [18], [19] and [20]. This has also been found in CFS patients [5], [6], [7] and [10]. Psychological distress might impede changes in fatigue related cognitions during therapy and thus result in a poor therapy response. Second, childhood maltreatment may result in interpersonal problems later in life, 
Heins, M.J., Knoop, H., Lobbestael, J., Bleijenberg, G. Childhood maltreatment and the response to cognitive behavior therapy for chronic fatigue syndrome. Journal of Psychosomatic Research: 2011, 71(6), 404-410

such as sensitivity to rejection, unstable or chaotic relationships and problems trusting others [21] and [22]. These interpersonal problems may also impede the psychotherapeutic relationship between patient and therapist, and thereby the therapy response. Third, Roberts et al. showed that CFS patients with hypocortisolism, i.e. low levels of the stress-related hormone cortisol, do show a poorer response to CBT [23]. Hypocortisolism has been related to childhood maltreatment [24], and Roberts et al. hypothesized that it might be a symptom perpetuating factor in CFS patients.

A poor therapy response of CFS patients with a history of childhood maltreatment could have clinical implications, like adding specific interventions aimed at reducing the level of psychological distress to the currently used treatment protocol to improve outcome for this subgroup. The aim of the current study is to determine whether the treatment response to CBT for CFS is impaired in patients with a history of childhood abuse. As McMahon et al. reported [25], the effect of childhood maltreatment may not appear in the direct treatment response, but rather in long-term results. The factors that lead to a greater vulnerability to become chronically fatigued, might also lead to a greater vulnerability to relapse after successful therapy. So in an exploratory analysis we also included 6-month follow-up data in our study.

\section{METHODS}

\section{Subjects}

The study population was selected from patients referred to our tertiary care CFS clinic for individual CBT. We included the 216 consecutively referred patients starting CBT between March 2008 and June 2009 who fulfilled the CDC criteria for CFS, were between 18 and 65 years of age and were able to read and write Dutch. Patients had to be severely fatigued, operationalized as having a score of 35 or higher on the subscale fatigue of the Checklist Individual Strength [26], and severely disabled, operationalized as having a score of 700 or higher on the Sickness Impact Profile [27], [28] and [29]. All referred patients received a standard medical examination at the outpatient clinic of our department of internal medicine, to rule out any somatic or psychiatric disorder that excludes the diagnosis of CFS. If patients had already been extensively medically examined prior to referral and somatic and psychiatric disorders that could explain the fatigue had already been ruled out, they were immediately referred to our treatment center. After this, all patients underwent a standard diagnostic procedure, consisting of a set of self-report questionnaires (including the questionnaires used for this study) and an interview with an experienced clinical psychologist. In this unstructured clinical interview, the psychiatric evaluation was extended to rule out current psychiatric disorders that excluded the diagnosis of CFS according to CDC criteria [3]. Patients who were currently applying for a disability claim were excluded until their application was completed, as this has been found to predict a poor therapy response [30].

\section{Treatment}

Patients followed CBT for CFS [31] and [32] according to the protocol that has previously been tested in several RCTs [33], [34] and [35]. The CBT consisted of 12 to 16 individual 1-hour sessions during approximately 6 months [31]. Patients were encouraged to systematically increase their activity, while concurrently fatigue 
Heins, M.J., Knoop, H., Lobbestael, J., Bleijenberg, G. Childhood maltreatment and the response to cognitive behavior therapy for chronic fatigue syndrome. Journal of Psychosomatic Research: 2011, 71(6), 404-410

perpetuating cognitions were challenged and personal goals, as set at the start of the therapy, were realized.

\section{Baseline assessment}

Besides sex and age, the following aspects of psychiatric comorbidity were assessed at baseline through self-report questionnaires: 1) prior treatment by a psychiatrist or psychologist (yes/no) 2) history and treatment of depression, anxiety, alcohol or eating problems (yes/no) 3) use of anti-depressants, anxiolytics or sedatives during the last 6 months (yes/no) and 4) current depressive symptoms as measured with the Beck Depression Inventory for Primary Care (BDI-PC)[36]. This short version consists of 7 of the original questions of the BDI-II (anhedonia, suicidal thoughts or wishes, pessimism, past failure, self-dislike, self-criticalness). A sum score can be calculated, with a maximum of 21 and a cut-off point of 4 defining clinical depression. Validity and reliability (Cronbach's alpha $=.86$, sensitivity and specificity $82 \%)$ are good.

\section{Assessment of childhood maltreatment}

Childhood maltreatment was assessed before therapy using the Dutch version of the Childhood Trauma Questionnaire-Short Form (CTQ-SF) [37] and [38]. This selfreport questionnaire, previously used by Heim et al. in their studies on CFS and childhood maltreatment [5] and [6], consists of 28 items measured on a 5 point Likert-scale. Five dimensions are discerned: 1) Physical Abuse 2) Emotional Abuse 3) Sexual Abuse 4) Physical Neglect 5) Emotional Neglect. Each subscale comprises 5 items and scores range from 5 to 25. For each subscale, cut-off scores for none-tolow, low-to-moderate and moderate-to-severe maltreatment are available. The Dutch version of the CTQ-SF has recently been validated in a sample of clinical and nonclinical patients and showed excellent reliability (Cronbach's alpha .91 for Physical Abuse, .89 for Emotional Abuse, .95 for Sexual Abuse, .63 for Physical Neglect and .91 for Emotional Neglect) [38].

We used the cut-off scores for moderate-to-severe maltreatment to classify individuals as positive on a given subscale. These are $\geq 13$ for Emotional Abuse, $\geq 10$

for Physical Abuse, $\geq 8$ for Sexual Abuse, $\geq 15$ for Emotional Neglect, and $\geq 10$ for Physical Neglect [39]. Norms were derived from six samples, three of which comprise 2001 of the 2201 individuals in the CTQ norm group: (a) 1225 all female, mostly White HMO members (b) 378 mostly Black, male inpatient substance abusers; and (c) 398 adolescent psychiatric inpatients.

\section{Assessment of treatment outcome}

To assess treatment outcome, patients' levels of fatigue, impairment, and psychological distress were measured both before and after CBT. In addition, fatigue and impairment were also assessed 6 months after therapy. Fatigue was assessed with the subscale fatigue severity of the Checklist Individual Strength (CIS)[40]. This subscale indicates the level of fatigue in the previous two weeks, and consists of eight items on a seven point scale (range 8-56). A score of 35 and higher (i.e. 2 standard deviations above the mean of a healthy control group) indicates severe fatigue. Cronbach's alpha ranges from .83 to .92[26] and [41]. Functional impairment was assessed by the Sickness Impact Profile (SIP) 8 [27], [28] and [29]. This version of the SIP consists of 8 different subscales measuring limitations in multiple aspects 
Heins, M.J., Knoop, H., Lobbestael, J., Bleijenberg, G. Childhood maltreatment and the response to cognitive behavior therapy for chronic fatigue syndrome. Journal of Psychosomatic Research: 2011, 71(6), 404-410

of daily functioning, as well as a total score measuring overall impairment. A total score of at least 700 indicates severe impairment[15], [26] and [34]. The overall Cronbach's alpha of the Dutch version is .91 [42]. In addition, limitations in physical functioning were measured with the corresponding subscale of the Medical Outcomes Survey SF36[43]. Scores range from 0 (maximum limitations) to 100 (no limitations). The Cronbach's alpha of the subscale physical functioning of the Dutch version is .92 [44]. Psychological distress was measured with the Symptom checklist 90 (SCL90) [45], which consists of 90 items measured on a 5 point Likert scale. The total score ranges from 90 to 450, with higher scores indicating more psychological distress. This widely used questionnaire has good reliability and validity, Cronbach's alpha of the subscales ranges from .73 to .89 [46].

\section{Data analyses}

To ascertain that the level of childhood abuse was indeed increased in our patients, we compared the prevalence of childhood maltreatment in our CFS patients to that of 227 Dutch controls, previously described by Thombs et al. [38]. Controls were recruited via advertisements, flyers, or personal contacts through the researchers. Exclusion criteria included (past) psychiatric complaints, alcohol or drug intoxication, an IQ of $<80$, and the inability to independently complete the CTQ-SF. Persons with medical conditions were not excluded.

Childhood maltreatment was defined according to the cut-off point for moderate to severe maltreatment for the different subscales of the CTQ-SF [39]. We calculated Odds Ratios and 95\% confidence intervals, adjusted for sex and age, using unconditional logistic regression, to estimate the relative risk of having CFS in patients with or without (a subtype of) childhood maltreatment.

Next, we divided the CFS patients that started CBT into groups with and without childhood maltreatment, i.e. those scoring above the cut-off on one or more subscales of the CTQ-SF, whom we then compared on demographic characteristics (sex, age), psychiatric comorbidity and baseline CFS symptoms (fatigue, impairment). Before comparing treatment response in patients with and without childhood maltreatment, we first assessed overall treatment effectiveness by calculating the uncontrolled effect size for the subscale fatigue of the CIS. We performed a sensitivity analysis using 3 different methods to calculate the effect size (last observation carried forward, completers analysis, or single imputation based on the pre-treatment value). Subsequently, treatment response was assessed by calculating the mean change during therapy in the outcome measures. We compared these change scores between patients with and without any childhood maltreatment using analysis of variance. In uncontrolled designs, this approach results in less bias [47]. In addition, we assessed two moderators of the possible effect of childhood maltreatment on the response to CBT. We compared the effect of different subtypes of childhood maltreatment by comparing the mean change scores on the outcome measures between patients scoring above or below the cut-off point for moderate to severe maltreatment for each subscale separately. As psychological symptoms might also moderate a possible relationship between childhood trauma and treatment response, we also performed three regression analyses with change in CIS fatigue as the dependent variable and 1) childhood maltreatment status, 2) either pre-treatment BDI-PC score, SCL subscale depression, or SCL sum score depression+anxiety 3) an interaction variable of both, as independent variables. 
Heins, M.J., Knoop, H., Lobbestael, J., Bleijenberg, G. Childhood maltreatment and the response to cognitive behavior therapy for chronic fatigue syndrome. Journal of Psychosomatic Research: 2011, 71(6), 404-410

Numbers were calculated on an intention to treat basis. Missing values on the postmeasurement were replaced with estimates derived from single imputation (missing variable analysis, regression with baseline value as predictor) [48]. Distribution of continuous variables was inspected visually and non-parametric tests were used and median (interquartile range) reported when the distribution of a variable was skewed.

\section{RESULTS}

\section{Childhood maltreatment: comparison with healthy controls}

Eighty of the 216 CFS patients (37\%) and 37 of the 227 controls (16\%) reported childhood maltreatment. Especially a history of emotional abuse and neglect, and physical abuse was more common in CFS patients (see Table 1).

\section{[TABLE 1]}

\section{Baseline characteristics of patients with/without childhood maltreatment}

CFS patients reporting a history of childhood maltreatment were significantly older, and more often had a life-time history of depression (44\% vs. 25\%) and depression related treatment (34\% vs. 22\%) than patients reporting no childhood maltreatment. Current levels of depressive symptoms measured with the BDI-PC, were also significantly higher in patients reporting childhood maltreatment. They reported significantly more limitations, as measured with the SIP, and a higher level of psychological distress (see Table 2).

\section{[TABLE 2]}

\section{Treatment response in patients with/without childhood maltreatment}

Data of the post-measurement were missing for 24 patients. The uncontrolled Cohen's d for the change in CIS subscale fatigue ranged from 1.64 to 2.13, depending on the method of imputation (last observation carried forward, completers analysis, or single imputation based on the pre-treatment value) [49]. This is comparable to a statistical benchmark testing the efficacy of CBT for CFS based on previously conducted RCTs (1.44, 95\% CI 0.97-1.89) [50]. Mean treatment duration (8.0 (sd 3.9) vs. 8.3 (sd 4.7)) and number of sessions (10.6 (sd 5.4) vs. 11.0 (sd 5.2)) were comparable between patients with and without a history of childhood maltreatment ( $p=.72$ and $p=.62$ respectively).

Mean pre and post treatment values of the main outcome measures, stratified by childhood maltreatment status, are depicted in Fig. 1. We did not find a statistically significant difference between the two subgroups in the amount of change on any of the outcome measures (see Table 3). However, the level of limitations and psychological distress of patients reporting childhood maltreatment remained significantly higher after treatment (median SIP total score 653 (333-1188) vs. 401 (64-689), Mann-Whitney $U$ test $(\mathrm{df}=214) \mathrm{z}=-39 \mathrm{p}<.001$; median SCL total score 135 (113-155) vs. 120 (102-142), Mann Whitney $U$ test $(\mathrm{df}=214) \mathrm{z}=-3.2 \mathrm{p}=0.001$; median SF36 physical functioning 85 (70-95) vs. 90 (76-95) Mann Whitney $U$ test $(d f=214) z=-2.23 p=0.03)$. 
Heins, M.J., Knoop, H., Lobbestael, J., Bleijenberg, G. Childhood maltreatment and the response to cognitive behavior therapy for chronic fatigue syndrome. Journal of Psychosomatic Research: 2011, 71(6), 404-410

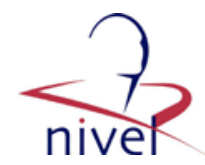

\section{[TABLE 3][FIGURE 1]}

Moderation by subtype of childhood maltreatment and psychological symptoms Change scores in the outcome measures were compared between patients scoring above and below the cut-off point for moderate to severe maltreatment for each of the maltreatment subtypes. We compared the patients with a certain subtype of maltreatment to all other patients. No significant differences were found on any subscale between patients with and without a specific type of childhood maltreatment.

Linear regression revealed that change in CIS fatigue, controlled for childhood maltreatment status, was not significantly affected by psychological symptoms, measured with the BDI-PC, SCL depression or a sum score of the SCL subscales depression and anxiety. (beta=.56 ( $\mathrm{p}=.28), .11(\mathrm{p}=.48)$ and $.09(\mathrm{p}=.37)$ respectively). Interaction terms were all non-significant (beta=- .37 ( $\mathrm{p}=.61),-.07(\mathrm{p}=.75)$ and - .08 ( $\mathrm{p}=.57))$ indicating that psychological symptoms did not moderate the relationship between childhood maltreatment and change in CIS fatigue.

\section{Long-term treatment response}

We performed an explorative analysis on the six-month follow-up data. Of the 189 patients with a post-treatment measurement, 141 (76\%) also had follow-up data. Based on the available data, mean scores in fatigue and impairment between the measurement right after treatment and 6 months later were calculated. No significant differences were found between the group of patients with and without a history of childhood maltreatment. Mean levels of fatigue in patients with childhood maltreatment changed from 24.73 (sd 11.91) post-therapy to 26.04 (sd 12.7) at follow-up and in patients without childhood maltreatment from 23.23 (sd 11.99) to 26.39 (sd 13.20) respectively. Mean levels of impairment in patients with childhood maltreatment changed from 605 (sd 608) post-treatment to 576 (sd 690) at follow-up and in patients without childhood maltreatment from 357 (sd 415) post-treatment to 399 (sd 446) at follow-up. The amount of change was not significantly different between both groups of patients (fatigue: two-tailed $t$-test $(\mathrm{df}=141) \mathrm{t}=1.55 \mathrm{p}=.13$; impairment: two-tailed $t$-test $(\mathrm{df}=141) \mathrm{t}=1.56 \mathrm{p}=.12)$.

\section{DisCUSSION}

\section{Main findings}

As far as we know, this is the first study that examined whether a history of childhood maltreatment is related to the treatment response in CBT for CFS. We replicated the finding that CFS patients more often report a history of childhood maltreatment than healthy subjects. However, we found no differences in the change during therapy in fatigue, limitations or psychological distress between patients with or without a history of childhood maltreatment. Neither did we find differences between the treatment effect in groups of patients with different subtypes of childhood maltreatment, although our power may have been insufficient for some subtypes to detect changes between subgroups. Our results indicate that CBT was as effective for patients with a history of childhood maltreatment as for those without such a history. Also at 6-months follow-up, no differences were found between patients with and without a history of childhood maltreatment, but results of this 
Heins, M.J., Knoop, H., Lobbestael, J., Bleijenberg, G. Childhood maltreatment and the response to cognitive behavior therapy for chronic fatigue syndrome. Journal of Psychosomatic Research: 2011, 71(6), 404-410

explorative analysis should be interpreted with caution because of the high percentage of missing data (24\%).

Although both groups did not differ in the level of fatigue (before and after CBT), patients with a history of childhood maltreatment did report more psychological symptoms (i.e. a higher level of psychological distress and depressive symptoms) and a higher level of disabilities both before and after CBT. These findings could suggest that although fatigue and fatigue related limitations are reduced by CBT, problems related to the childhood maltreatment or its long term consequences are not. This is not a surprising finding as this specific form of CBT developed to treat CFS is only focused on cognitions and behaviors specifically related to CFS symptoms. Prins et al. found similar results when comparing effects of CBT in CFS patients with and without psychiatric comorbidity [51].

\section{Comparison with existing literature}

There are only a few studies that investigated the effect of childhood maltreatment on the response to behavioral interventions. Some of them did find a relationship with treatment outcome in other disorders. A recent study showed that in a residential substance abuse program, patients with a history of childhood maltreatment did not respond as well as patients without a history of childhood abuse [52]. In CBT for depression, a poor treatment response was found in adolescent patients with a history of childhood maltreatment, i.e. sexual abuse [53]. Perhaps this can be understood in the light of the negative effect abuse can have on self-esteem. This could negatively interfere with the response to CBT for depression, in which the reformulation of negative self-evaluations is crucial. CFS is not characterized by a negative view of the self, but rather by specific cognitions regarding somatic experiences and the ability to perform activities[16] and [54]. This could explain why childhood maltreatment does not seem to have a direct influence on the response to CBT for CFS.

When the traumatic experiences and their consequences are incorporated into the treatment, as in a behavioral intervention for recurrent depression (Cognitive Behavioral Analysis System of Psychotherapy, CBASP) patients with a history of maltreatment actually respond better than those without [55]. In a study on CBT for deliberate self-harm, patients with a history of childhood maltreatment also showed a more favorable treatment response [56]. As deliberate self-harm is likely to be closely related to the traumatic experiences, it is also likely that these experiences are incorporated into the treatment. This will make it more likely that patients with a history of childhood maltreatment will profit from treatment.

Two studies reported on the effect of childhood maltreatment on treatments for somatic complaints. One study, reporting on the treatment of patients with spinal disorder, also found that the direct effects of the behavioral intervention were comparable, although the level of psychological disturbances was substantially higher in patients with a history of childhood maltreatment [25]. This corresponds with our own findings. Interestingly, in a study testing the effectiveness of psychodynamic interpersonal therapy for irritable bowel syndrome (IBS), childhood maltreatment was in fact linked to a good response [57]. In both IBS and CFS childhood maltreatment is a predisposing risk marker [58] and [59].

According to Craighead and Nemeroff [60] treatment effects in patients with a history of childhood maltreatment are stronger when a treatment concurrently addresses several dimensions of the problem. Psychodynamic interpersonal therapy 
Heins, M.J., Knoop, H., Lobbestael, J., Bleijenberg, G. Childhood maltreatment and the response to cognitive behavior therapy for chronic fatigue syndrome. Journal of Psychosomatic Research: 2011, 71(6), 404-410

is focused on the interpersonal difficulties patients experience that are thought to maintain symptoms. It has a broader scope than CBT for CFS, which is only aimed at symptom specific behaviors and thoughts. This broader scope may explain the good therapy response of the subgroup of IBS patients with a history of abuse. It is likely that the disabilities and psychological distress of this subgroup are not only determined by specific somatic symptoms, but also by other consequences of the maltreatment. In a more specific symptom focused intervention, such as CBT for CFS, the psychological and interpersonal problems associated with the childhood maltreatment may not be addressed. This could explain why in our study, patients with a history of childhood maltreatment continued to experience increased levels of psychological distress and limitations after CBT, while at the same time their pattern of change in CFS symptoms and disabilities was comparable to patients without a history of childhood maltreatment. Rather than extending the current protocol of CBT for CFS, additional therapy directly focusing on the traumatic experiences and their consequences, may be effective in further reducing distress and limitations in those patients with a history of childhood maltreatment who still report substantial psychological distress and limitations.

\section{Limitations}

Our study was uncontrolled, so we cannot compare the results of patients following CBT to an untreated control group. A randomized clinical trial would have been the optimal way to determine the effect of childhood maltreatment on the outcome of CBT [61]. We cannot exclude that when we had used a controlled approach, we would have found an effect of childhood maltreatment, but we feel this is unlikely, as the course of fatigue would then have to be different in the controls with and without a history of childhood maltreatment.

The diagnosis of CFS was based on an evaluation by a medical specialist. The medical evaluation was performed in a standardized way at the department of internal medicine of the Radboud University Medical Centre and included the necessary elements as mentioned in the Fukuda criteria [3]. When the medical evaluation had already been done by the general practitioner or another medical specialist (minority of the cases) we made sure that the evaluation also included these elements. We did not use a standardized interview for the evaluation of current or past psychiatric disorders, which may be considered a limitation. However, we assured that the additional psychological evaluation performed at the treatment centre also included the elements as stated in the Fukuda criteria [3].

For the assessment of childhood maltreatment we relied on retrospective and uncorroborated self-report. Although the CTQ-SF is well-validated, and has been used before in CFS populations, participants might still be underreporting, e.g. due to forgetting, ignorance or intentional non-disclosure [62]. However, a meta-analysis of Hardt et al. showed that retrospective recall of childhood maltreatment is valid enough to be used in case-control studies [62]. Another limitation might be that sick individuals may more easily report childhood maltreatment, as they might see this as a possible cause of their symptoms.

The cut-off scores we used to define childhood maltreatment have been calculated based on a population from the US. Mean scores on the CTQ-SF in the Dutch population are somewhat lower [38], so these cut-off scores might have been too strict for our study. This could have led to an underestimation of the percentage of 
Heins, M.J., Knoop, H., Lobbestael, J., Bleijenberg, G. Childhood maltreatment and the response to cognitive behavior therapy for chronic fatigue syndrome. Journal of Psychosomatic Research: 2011, 71(6), 404-410

patients with childhood maltreatment. But the comparison between patients with and without childhood maltreatment remains valid, as the more severe cases of childhood maltreatment, who are most likely to have a poor response to therapy, will have been classified correctly.

Because the CTQ-SF was part of the standard diagnostic procedure, the therapists treating the patients were not blinded for the outcome of the CTQ-SF. They may have adapted their approach in patients with a history of childhood maltreatment. However, our CBT program is protocolized and focuses on the cognitions and symptoms and specific cognitions related to (avoidance of) activity. We have no indication that therapists systematically deviated from the protocol as they stated that childhood maltreatment had only been discussed in the intake session.

\section{CONCLUSION}

Concluding, childhood maltreatment is not related to the direct treatment response of CBT for CFS, so in patients with a history of childhood maltreatment CFS symptoms can be treated with CBT just as well as in patients without such a history.

\section{REFERENCES}

[1] R Cairns, M Hotopf A systematic review describing the prognosis of chronic fatigue syndrome. Occup Med (Lond), 55 (1) (2005), pp. 20-31

[2] J Hardt, D Buchwald, D Wilks, M Sharpe, WA Nix, U.T. Egle Health-related quality of life in patients with chronic fatigue syndrome: an international study.J of Psychosom Res, 51

(2) (2001), pp. 431-434

[3] K Fukuda, SE Straus, I Hickie, MC Sharpe, JG Dobbins, A Komaroff The chronic fatigue syndrome: a comprehensive approach to its definition and study. International Chronic Fatigue Syndrome Study Group. Ann Intern Med, 121 (12) (1994), pp. 953-959

[4] WC Reeves, A Lloyd, SD Vernon, N Klimas, LA Jason, G Bleijenberg et al. Identification of ambiguities in the 1994 chronic fatigue syndrome research case definition and recommendations for resolution BMC Health Serv Res, 3 (1) (2003), p. 25

[5] C Heim, UM Nater, E Maloney, R Boneva, JF Jones, WC Reeves Childhood trauma and risk for chronic fatigue syndrome: association with neuroendocrine dysfunction Arch Gen Psychiatry, 66 (1) (2009), pp. 72-80

[6] C Heim, D Wagner, E Maloney, DA Papanicolaou, L Solomon, JF Jones et al. Early adverse experience and risk for chronic fatigue syndrome: results from a population-based study Arch Gen Psychiatry, 63 (11) (2006), pp. 1258-1266

[7] J McCauley, DE Kern, K Kolodner, L Dill, AF Schroeder, HK DeChant et al. Clinical characteristics of women with a history of childhood abuse: unhealed wounds JAMA, 277 (17) (1997), pp. 1362-1368

[8] S Romans, C Belaise, J Martin, E Morris, A Raffi Childhood abuse and later medical disorders in women An epidemiological study. Psychother Psychosom, 71 (3) (2002), pp. 141-150

[9] RR Taylor, LA Jason Chronic fatigue, abuse-related traumatization, and psychiatric disorders in a community-based sample Soc Sci Med, 55 (2) (2002), pp. 247-256

[10] B Van Houdenhove, E Neerinckx, R Lysens, H Vertommen, L Van Houdenhove, $P$ Onghena et al. Victimization in chronic fatigue syndrome and fibromyalgia in tertiary care: a controlled study on prevalence and characteristics Psychosomatics, 42 (1) (2001), pp. 2128 
Heins, M.J., Knoop, H., Lobbestael, J., Bleijenberg, G. Childhood maltreatment and the response to cognitive behavior therapy for chronic fatigue syndrome. Journal of

Psychosomatic Research: 2011, 71(6), 404-410

[11] L Fisher, T Chalder Childhood experiences of illness and parenting in adults with chronic fatigue syndrome J Psychosom Res, 54 (5) (2003), pp. 439-443

[12] RR Taylor, LA Jason Sexual abuse, physical abuse, chronic fatigue, and chronic fatigue syndrome: a community-based study J Nerv Ment Dis, 189 (10) (2001), pp. 709-715

[13] JM Malouff, EB Thorsteinsson, SE Rooke, N Bhullar, NS Schutte Efficacy of cognitive behavioral therapy for chronic fatigue syndrome: a meta-analysis Clin Psychol Rev, 28 (5) (2008), pp. 736-745

[14] JR Price, E Mitchell, E Tidy, V Hunot Cognitive behaviour therapy for chronic fatigue syndrome in adults Cochrane Database Syst Rev (3) (2008), p. CD001027

[15] H Knoop, G Bleijenberg, MF Gielissen, JW van der Meer, PD White Is a full recovery possible after cognitive behavioural therapy for chronic fatigue syndrome? Psychother Psychosom, 76 (3) (2007), pp. 171-176

[16] H Knoop, JB Prins, R Moss-Morris, G Bleijenberg The central role of cognitive processes in the perpetuation of chronic fatigue syndrome J Psychosom Res, 68 (5) (2010), pp. 489-494

[17] JH Vercoulen, CM Swanink, JM Galama, JF Fennis, PJ Jongen, OR Hommes et al. The persistence of fatigue in chronic fatigue syndrome and multiple sclerosis: development of a model J Psychosom Res, 45 (6) (1998), pp. 507-517

[18] PE Mullen, JL Martin, JC Anderson, SE Romans, GP Herbison The long-term impact of the physical, emotional, and sexual abuse of children: a community study Child Abuse Negl, 20 (1) (1996), pp. 7-21

[19] KW Springer, J Sheridan, D Kuo, M Carnes Long-term physical and mental health consequences of childhood physical abuse: results from a large population-based sample of men and women Child Abuse Negl, 31 (5) (2007), pp. 517-530

[20] PE Mullen, SE Romans-Clarkson, VA Walton, GP Herbison Impact of sexual and physical abuse on women's mental health Lancet, 1 (8590) (1988), pp. 841-845

[21] PE Mullen, JL Martin, JC Anderson, SE Romans, GP Herbison The effect of child sexual abuse on social, interpersonal and sexual function in adult life Br J Psychiatry, 165 (2) (1994), pp. 35-47

[22] J Briere, CE Jordan Childhood maltreatment, intervening variables, and adult psychological difficulties in women: an overview Trauma Violence Abuse, 10 (4) (2009), pp. 375-388

[23] AD Roberts, ML Charler, A Papadopoulos, S Wessely, T Chalder, AJ Cleare Does hypocortisolism predict a poor response to cognitive behavioural therapy in chronic fatigue syndrome? Psychol Med, 40 (3) (2010), pp. 515-522

[24] CO Ladd, RL Huot, KV Thrivikraman, CB Nemeroff, MJ Meaney, PM Plotsky Long-term behavioral and neuroendocrine adaptations to adverse early experience Prog Brain Res, 122 (2000), pp. 81-103

[25] MJ McMahon, RJ Gatchel, PB Polatin, TG Mayer Early childhood abuse in chronic spinal disorder patients. A major barrier to treatment success Spine (Phila Pa 1976), 22 (20) (1997), pp. 2408-2415

[26] JH Vercoulen, CM Swanink, JF Fennis, JM Galama, JW van der Meer, G Bleijenberg Dimensional assessment of chronic fatigue syndrome J Psychosom Res, 38 (5) (1994), pp. 383-392

[27] M Bergner, RA Bobbitt, WE Pollard, DP Martin, BS Gilson The sickness impact profile: validation of a health status measure Med Care, 14 (1) (1976), pp. 57-67

[28] WE Pollard, RA Bobbitt, M Bergner, DP Martin, BS Gilson The sickness impact profile: reliability of a health status measure Med Care, 14 (2) (1976), pp. 146-155 
Heins, M.J., Knoop, H., Lobbestael, J., Bleijenberg, G. Childhood maltreatment and the response to cognitive behavior therapy for chronic fatigue syndrome. Journal of

Psychosomatic Research: 2011, 71(6), 404-410

[29] HM Jacobs, A Luttik, FW Touw-Otten, RA de Melker The sickness impact profile; results of an evaluation study of the Dutch version Ned Tijdschr Geneeskd, 134 (40) (1990), pp. 1950-1954

[30] JB Prins, E Bazelmans, S van der Werf, JWM van der Meer, G Bleijenberg Cognitive behaviour therapy for chronic fatigue syndrome: predictors of treatment outcome Int Congr Ser, 1241 (2002), pp. 131-135

[31] G Bleijenberg, JB Prins, E Bazelmans Cognitive behavioural therapies

LA Jason, PA Fennell, RR Taylor (Eds.), Handbook of chronic fatigue syndrome, Wiley \& Sons, New york (2003)

[32] H Knoop, G Bleijenberg Het chronisch vermoeidheidssyndroom: behandelprotocol cognitieve gedragstherapie voor CVS Bohn, Stafleu en van Loghum, Houten (2010)

[33] M Stulemeijer, LW de Jong, TJ Fiselier, SW Hoogveld, G Bleijenberg Cognitive behaviour therapy for adolescents with chronic fatigue syndrome: randomised controlled trial BMJ, 330 (7481) (2005), p. 14

[34] JB Prins, G Bleijenberg, E Bazelmans, LD Elving, TM de Boo, JL Severens et al. Cognitive behaviour therapy for chronic fatigue syndrome: a multicentre randomised controlled trial Lancet, 357 (9259) (2001), pp. 841-847

[35] M Tummers, H Knoop, G Bleijenberg

Effectiveness of stepped care for chronic fatigue syndrome: a randomized noninferiority trial J Consult Clin Psychol, 78 (5) (2010), pp. 724-731

[36]AT Beck, D Guth, RA Steer, R BallScreening for major depression disorders in medical inpatients with the Beck Depression Inventory for Primary Care

Behav Res Ther, 35 (8) (1997), pp. 785-791

[37] DP Bernstein, JA Stein, MD Newcomb, E Walker, D Pogge, T Ahluvalia et al. Development and validation of a brief screening version of the Childhood Trauma Questionnaire Child Abuse Negl, 27 (2) (2003), pp. 169-190

[38] BD Thombs, DP Bernstein, J Lobbestael, A Arntz A validation study of the Dutch Childhood Trauma Questionnaire-Short Form: factor structure, reliability, and knowngroups validity Child Abuse Negl, 33 (8) (2009), pp. 518-523

[39] D Bernstein, L Fink Childhood trauma questionnaire: a retrospective self-report questionnaire and manual Psychological Corp, San Antonio, Tex (1998)

[40] JH Vercoulen, E Bazelmans, CM Swanink, JF Fennis, JM Galama, PJ Jongen et al. Physical activity in chronic fatigue syndrome: assessment and its role in fatigue $\mathrm{J}$ Psychiatr Res, 31 (6) (1997), pp. 661-673

[41] JH Vercoulen, M Alberts, G Bleijenberg De checklist individual strength (CIS) Gedragstherapie, 32 (1999), pp. 31-36

[42] AF de Bruin, LP de Witte, F Stevens, JP Diederiks Sickness impact profile: the state of the art of a generic functional status measure Soc Sci Med, 35 (8) (1992), pp. 1003-1014

[43] AL Stewart, RD Hays, JE Ware Jr. The MOS short-form general health survey.

Reliability and validity in a patient population Med Care, 26 (7) (1988), pp. 724-735

[44] van der Zee K, Sanderman R. [Measuring overall health Status with the MOS SF36: a manual]. Groningen: Noordelijk Centrum voor Gezondheidsvraagstukken

[45] WA Arrindell, J Ettema SCL 90, handleiding bij een multidimensionele psychopathologie-indicator Lisse: Swets \& Zeitlinger BV (1986)

[46] LM Horowitz, SE Rosenberg, BA Baer, G Ureno, VS Villasenor Inventory of interpersonal problems: psychometric properties and clinical applications J Consult Clin Psychol, 56 (6) (1988), pp. 885-892

[47] GJ Van Breukelen ANCOVA versus change from baseline: more power in randomized studies, more bias in nonrandomized studies [corrected] J Clin Epidemiol, 59 (9) (2006), pp. 920-925 
Heins, M.J., Knoop, H., Lobbestael, J., Bleijenberg, G. Childhood maltreatment and the response to cognitive behavior therapy for chronic fatigue syndrome. Journal of

Psychosomatic Research: 2011, 71(6), 404-410

[48] A Dempster, N Laird, D Rubin Maximum Likelihood from incomplete data via the EM algorithm J of the Royal Stat Soc, Series B, 39 (1) (1977), pp. 1-38

[49] J Cohen Statistical power analysis for the behavioural sciences (2nd ed.)Erlbaum, Hillsdale, NJ (1988)

[50] K Scheeres, M Wensing, H Knoop, G Bleijenberg Implementing cognitive behavioral therapy for chronic fatigue syndrome in a mental health center: a benchmarking evaluation J Consult Clin Psychol, 76 (1) (2008), pp. 163-171

[51] J Prins, G Bleijenberg, EK Rouweler, J van der Meer Effect of psychiatric disorders on outcome of cognitive-behavioural therapy for chronic fatigue syndrome $\mathrm{Br} \mathrm{J}$ Psychiatry, 187 (2005), pp. 184-185

[52] JY Sacks, K McKendrick, S Banks The impact of early trauma and abuse on residential substance abuse treatment outcomes for women J Subst Abuse Treat, 34 (1) (2008), pp. 90-100

[53] CC Lewis, AD Simons, LJ Nguyen, JL Murakami, MW Reid, SG Silva et al. Impact of childhood trauma on treatment outcome in the Treatment for Adolescents with Depression Study (TADS) J Am Acad Child Adolesc Psychiatry, 49 (2) (2010), pp. 132-140

[54] R Moss-Morris, KJ Petrie Discriminating between chronic fatigue syndrome and depression: a cognitive analysis Psychol Med, 31 (3) (2001), pp. 469-479

[55] CB Nemeroff, CM Heim, ME Thase, DN Klein, AJ Rush, AF Schatzberg et al. Differential responses to psychotherapy versus pharmacotherapy in patients with chronic forms of major depression and childhood trauma Proc Natl Acad Sci USA, 100 (24) (2003), pp.

14293-14296

[56] P Spinhoven, N Slee, N Garnefski, E Arensman Childhood sexual abuse differentially predicts outcome of cognitive-behavioral therapy for deliberate self-harm J Nerv Ment Dis, 197 (6) (2009), pp. 455-457

[57] F Creed, E Guthrie, J Ratcliffe, L Fernandes, C Rigby, B Tomenson et al. Reported sexual abuse predicts impaired functioning but a good response to psychological treatments in patients with severe irritable bowel syndrome Psychosom Med, 67 (3) (2005), pp. 490-499

[58] WT Hamilton, AM Gallagher, JM Thomas, PD White Risk markers for both chronic fatigue and irritable bowel syndromes: a prospective case-control study in primary care Psychol Med, 39 (11) (2009), pp. 1913-1921

[59] G.E. Tietjen, J.L. Brandes, B.L. Peterlin, A. Eloff, R.M. Dafer, M.R. Stein et al. Childhood maltreatment and migraine (part III) Association with comorbid pain conditions. Headache, 50 (1) (2010), pp. 42-51

[60] WE Craighead, CB Nemeroff The impact of early trauma on response to psychotherapy Clin Neurosci Res, 4 (5-6) (2005), pp. 405-411

[61] HC Kraemer, GT Wilson, CG Fairburn, WS Agras Mediators and moderators of treatment effects in randomized clinical trials Arch Gen Psychiatry, 59 (10) (2002), pp. 877883

[62] J Hardt, M Rutter Validity of adult retrospective reports of adverse childhood experiences: review of the evidence J Child Psychol Psychiatry, 45 (2) (2004), pp. 260-273 
Heins, M.J., Knoop, H., Lobbestael, J., Bleijenberg, G. Childhood maltreatment and the response to cognitive behavior therapy for chronic fatigue syndrome. Journal of Psychosomatic Research: 2011, 71(6), 404-410

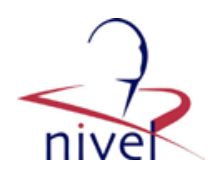

\section{FIGURE AND TABLES}

\section{Table 1}

Logistic regression models estimating the chance of having CFS relative to childhood maltreatment exposure in CFS cases and controls

\begin{tabular}{llclc}
\hline Predictor & \multicolumn{4}{l}{$\mathrm{N}(\%)$ above cut-off } \\
\cline { 2 - 5 } & $\begin{array}{l}\text { CFS } \\
(\mathrm{n}=216)\end{array}$ & $\begin{array}{c}\text { Controls } \\
(\mathrm{n}=227)\end{array}$ & OR $(95 \% \mathrm{CI})$ & p-value $^{\mathrm{a}}$ \\
\hline Emotional Abuse & $27(13)$ & $8(4)$ & $3.35(1.44-7.83)$ & .005 \\
Physical Abuse & $12(6)$ & $3(1)$ & $4.69(1.23-17.89)$ & .02 \\
Sexual Abuse & $21(10)$ & $10(4)$ & $1.94(0.87-4.36)$ & .11 \\
Emotional Neglect & $52(24)$ & $19(8)$ & $2.87(1.59-5.18)$ & $<.001$ \\
Physical Neglect & $28(13)$ & $15(7)$ & $1.89(0.95-3.78)$ & .07 \\
Any category & $80(37)$ & $37(16)$ & $2.73(1.70-4.39)$ & $<.001$ \\
\hline
\end{tabular}

Abbreviations: $\mathrm{CFS}=$ chronic fatigue syndrome; $\mathrm{Cl}=$ confidence interval; $\mathrm{OR}=\mathrm{Odds}$ Ratio.

Controls are also described in the Study of Thombs et al. [38].

Childhood Trauma Questionnaire cut-off scores for moderate to severe maltreatment were used to define childhood maltreatment [39]: Emotional Abuse $\geq 13$; Physical Abuse $\geq 10$; Sexual Abuse $\geq 8$; Emotional Neglect $\geq 15$; Physical Neglect $\geq 10$.

Models were adjusted for age and sex.

${ }^{\text {a }}$ Wald $\chi^{2}$ test. 
Heins, M.J., Knoop, H., Lobbestael, J., Bleijenberg, G. Childhood maltreatment and the response to cognitive behavior therapy for chronic fatigue syndrome. Journal of

Psychosomatic Research: 2011, 71(6), 404-410

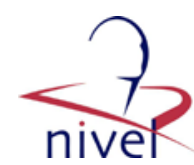

Table 2

Baseline characteristics of CFS patients reporting no childhood maltreatment vs. those reporting moderate to severe maltreatment on at least one subscale of the CTQ SF.

\begin{tabular}{|c|c|c|c|c|}
\hline & No $\mathrm{CM}(\mathrm{n}=136)$ & $\mathrm{CM}(\mathrm{n}=80)$ & Statistic & p-value \\
\hline \multicolumn{5}{|l|}{ Demographics } \\
\hline Female & $101(81 \%)$ & $62(87 \%)$ & .54 & .46 \\
\hline Age (years) & $35.2(11.2)$ & $39.1(10.3)$ & 2.54 & .01 \\
\hline \multicolumn{5}{|l|}{ Psychiatric comorbidity } \\
\hline \multicolumn{5}{|l|}{ Life-time } \\
\hline Depression & $34(25 \%)$ & $35(44 \%)$ & 7.94 & .005 \\
\hline Anxiety disorder & $21(15 \%)$ & $17(21 \%)$ & 1.12 & .29 \\
\hline Eating disorder & $5(4 \%)$ & $4(5 \%)$ & .22 & .65 \\
\hline Problematic alcohol use & $2(2 \%)$ & $1(1 \%)$ & .02 & .89 \\
\hline Visited psychiatrist & $8(6 \%)$ & $17(21 \%)$ & 11.6 & .001 \\
\hline Visited psychologist & $19(7 \%)$ & $6(8 \%)$ & .06 & .81 \\
\hline Treatment for depression & $30(22 \%)$ & $27(34 \%)$ & 3.54 & .06 \\
\hline \multicolumn{5}{|l|}{ Current } \\
\hline Antidepressants (last 6 months) & $16(12 \%)$ & $21(26 \%)$ & 6.74 & .009 \\
\hline Sedatives/anxiolytics (last 6 months) & $26(19 \%)$ & $18(23 \%)$ & .20 & .65 \\
\hline BDI-PC & $2.7(2.3)$ & $3.9(3.0)$ & 3.36 & $<.001$ \\
\hline \multicolumn{5}{|l|}{ CFS symptoms } \\
\hline CIS fatigue & $49.9(4.6)$ & $49.7(5.6)$ & -.250 & .80 \\
\hline SIP total & $1432(557)$ & $1715(553)$ & 3.62 & $<.001$ \\
\hline SF36 physical functioning & $58.2(19.5)$ & $53.6(19.6)$ & -1.70 & .09 \\
\hline SCL total ${ }^{*}$ & $153.0(137-179.8)$ & $173.5(155-206.8)$ & -4.27 & $<.001$ \\
\hline
\end{tabular}

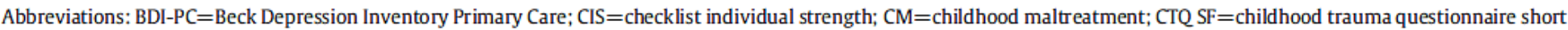
form; SCL=Symptom checklist 90; SF36=short form 36 health survey; SIP=sickness impact profile.

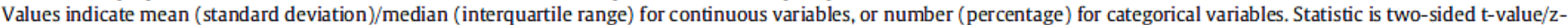
value, $(\mathrm{df}=214)$ for continuous variables, or $\chi^{2}$ value $(\mathrm{df}=1)$ for categorical variables.

Psychiatric comorbidity is life-time, unless otherwise stated. 
Heins, M.J., Knoop, H., Lobbestael, J., Bleijenberg, G. Childhood maltreatment and the response to cognitive behavior therapy for chronic fatigue syndrome. Journal of Psychosomatic Research: 2011, 71(6), 404-410

Fig. 1. Line diagrams of pre and post treatment values of the main outcome measures, stratified by childhood maltreatment status. CIS=checklist individual strength; $\mathrm{CM}=$ childhood maltreatment; CTQ SF=childhood trauma questionnaire short form; SCL=Symptom checklist 90; SF36=short form 36 health survey; $\mathrm{SIP}=$ sickness impact profile. Error bars indicate standard error of the mean.
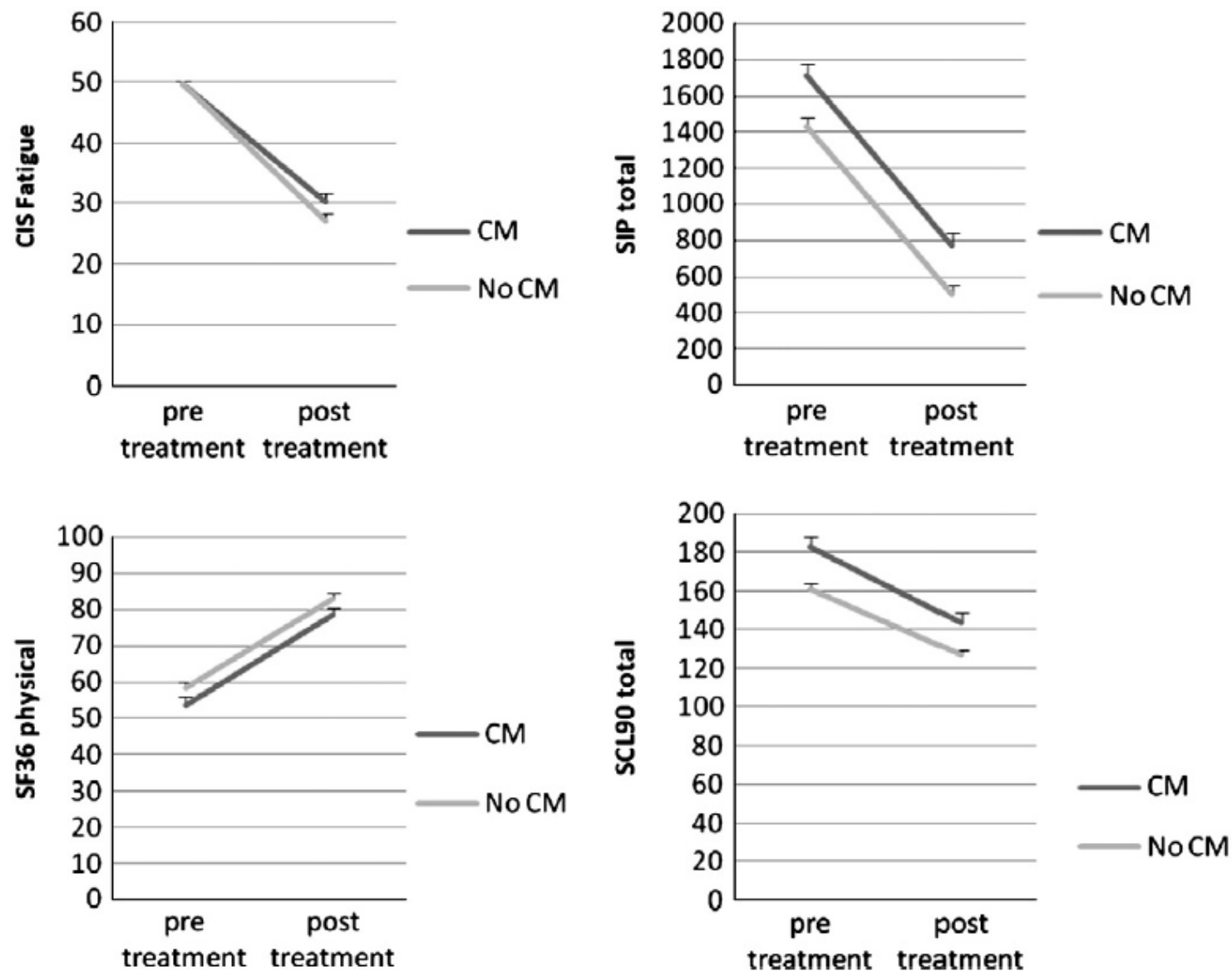

Table 3

Change scores of the outcome measures in patients with and without childhood maltreatment (imputation)

\begin{tabular}{|c|c|c|c|c|}
\hline & \multicolumn{4}{|l|}{ Mean change (sd) } \\
\hline & No CM $(n=136)$ & $C M(n=80)$ & $\begin{array}{l}\text { Statistic. } \\
\mathrm{t}_{214} / \mathrm{z}_{214}\end{array}$ & p-value \\
\hline as fatigue & $-22.8(13.4)$ & $-19.3(14.5)$ & 1.79 & .08 \\
\hline SIP total & $-926(713)$ & $-943(675)$ & -.17 & .87 \\
\hline SF36 physical functioning & $24.7(22.3)$ & $24.8(20.9)$ & .021 & .99 \\
\hline SCL90 total & $-35.5(-50.0--14.3)$ & $-43.0(-68.0--18.25)$ & -1.86 & .06 \\
\hline
\end{tabular}

Abbreviations: $\mathrm{CIS}=$ checklist individual strength; $\mathrm{CM}=$ childhood maltreatment; $\mathrm{SCL}=$ Symptom checklist 90 ; SF36=short form 36 health survey; SIP=sickness impact profile. Change is pre treatment value subtracted from post treatment value.

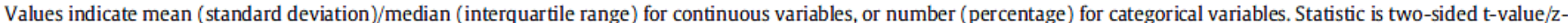
value, $(\mathrm{df}=214)$ for continuous variables, or $\chi^{2}$ value $(\mathrm{df}=1)$ for categorical variables.

Childhood maltreatment is defined as scoring above the cut-off for moderate to severe maltreatment on one or more subscales of the CTQ-SF [32]. 